\title{
Leutenheim - Hexenberg
}

Marina Lasserre

URL : http://journals.openedition.org/adlfi/8284

ISSN : 2114-0502

Éditeur

Ministère de la culture

Référence électronique

Marina Lasserre, "Leutenheim - Hexenberg », ADLFI. Archéologie de la France - Informations [En ligne], Alsace, mis en ligne le 01 mars 2001, consulté le 22 avril 2019. URL : http://journals.openedition.org/ adlfi/8284

Ce document a été généré automatiquement le 22 avril 2019

(c) Ministère de la Culture et de la Communication, CNRS 


\title{
Leutenheim - Hexenberg
}

\author{
Marina Lasserre
}

Identifiant de l'opération archéologique :

Date de l'opération : 2001 (FP)

Deux secteurs ont été fouillés lors de cette campagne, le secteur 30 (déjà décapé en 2000) et le secteur 31 qui est un élargissement du secteur 30.

En rebord du plateau, on a pu fouiller une vaste zone d'extraction de matériau qui a été recoupée par la palissade puis dans un second temps par sa réfection. Cette vaste fosse dont le volume extrait a été estimé à une trentaine de $\mathrm{m}^{3}$, semble s'organiser en deux lignes de surcreusements globalement circulaires dans le fond desquels il a pu être trouvé deux fois des rejets qui ont été assimilés à des petits "dépôts", dont un avec une mandibule humaine retournée.

Le matériel retrouvé ne présente aucune particularité notable par rapport au corpus déjà connu sur le site. La zone d'extraction a livré environ $80 \mathrm{~kg}$ de tessons de divers gabarits.

\section{INDEX}

Index géographique : Alsace, Bas-Rhin, Leutenheim

Index chronologique : Bronze final

operation Fouille programmée (FP) 


\section{AUTEURS}

\section{MARINA LASSERRE}

Sous-direction de l'Archéologie 